\title{
Editorial: Energy Recovery From Agro-Food Waste
}

\author{
Francisco Jesús Fernández Morales* \\ Chemical Engineering Department, Instituto de Tecnologías Química y Medioambiental (ITQUIMA), University of Castilla-La \\ Mancha, Ciudad Real, Spain
}

Keywords: agro-food wastes, characterization, management, energy conversion, operational conditions, modeling, business case

\section{Editorial on the Research Topic}

\section{Energy Recovery from Agro-Food Waste}

Climate change is one of the most significant challenges of our time. Food waste generation is also a growing problem in our society (USEPA, 2020a). Nowadays, the main food-waste management options and the final disposal in landfills negatively affects the climate change due to the emission of greenhouse gases (methane and nitrogen oxides). The waste hierarchy identifies the best options for waste management, offering alternative solutions to landfills, intending to consider waste a valuable resource. More recently, one of the priorities has been to recycle as much of the material and energy

OPEN ACCESS

Edited by:

Maria Pilar Bernal,

Center for Edaphology and Applied

Biology of Segura, Spanish National

Research Council (CSIC), Spain

Reviewed by:

Ariel A. Szogi,

Agricultural Research Service,

United States Department of

Agriculture (USDA), United States

*Correspondence:

Francisco Jesús Fernández Morales

fcojesus.fmorales@uclm.es

Specialty section:

This article was submitted to

Waste Management in

Agroecosystems,

a section of the journal

Frontiers in Sustainable Food Systems

Received: 10 December 2021

Accepted: 30 December 2021

Published: 21 January 2022

Citation:

Fernández Morales FJ (2022) Editorial:

Energy Recovery From Agro-Food

Waste.

Front. Sustain. Food Syst. 5:833178.

doi: 10.3389/fsufs. 2021.833178 contained in generated waste as possible. Only after extracting the maximum value from waste can a sustainable society be reached.

Additionally, fossil fuels for energy generation is one of the primary sources of atmospheric emissions causing climate change. This problem is also continuously growing because of the increasing demand for energy worldwide. The environmental impact cannot be solved only by reducing the energy demand, as access to energy is required to achieve an improved quality of life, as well as for economic development.

A good solution considering the energy and food waste problems could be converting food waste into energy (USEPA, 2020b). One of the most widely generated kinds of waste is agro-food waste. Agro-food waste has a tremendous renewable energy potential because this waste is characterized by its high organic load and biodegradability (Osman et al., 2019). Moreover, due to its relationship with food production, agro-food waste is unavoidably generated. The recovery of energy from these kinds of waste offers an excellent opportunity to obtain value. At the same time, the waste is stabilized, ultimately resulting in a double advantage.

The energy produced from agro-food waste presents minimal environmental impact and can be considered clean and renewable energy. The recovery of energy from agro-food waste integrates conversion processes (physical, chemical, electrochemical, and biological) to produce heat energy, fuels (methane, hydrogen, ethanol, etc.) and electrical energy. There are a vast number of processes that can be utilized to extract the energy contained in agro-food waste and most of them still require exploration.

To respond to this challenge, we have compiled a collection of research articles dedicated to the many facets of Energy Recovery from agro-food waste. Agro-food wastes represent a significant share of the energy sources used at the same time that means an environmental integration of waste management with sustainable energy generation.

The papers presented here address the topic from different perspectives, physicochemical and biological, providing readers with a range of questions and challenges associated with the Energy Recovery from Agro-Food Waste. The subjects examined in this issue are wide-ranging, from the benefits of the expanded granular sludge bed reactors for the biological transformation of acid brewery spent grain leachate, to the energy recovery of different residual biomass from cocoa and 
coffee mucilage as well as swine manure, to the modelization of the anaerobic processes related to the energy valorization to improve the design and operation of the processes, to the energetic valorization of cereal and coffee wastes through of co-digestion, to the hydrothermal liquefaction of food wastes. Several themes emerge from this compendium. Preeminent among them are the: (i) importance of agro-food waste management, (ii) feasibility of different management approaches, and (iii) energy recovery potential of agro-food wastes. There are numerous overlaps among themes. For instance, wastes characterization, blending mixtures, methane and hydrogen generation and energy consumption ratios (ECR) amongst others.

The theme of physicochemical treatments, using Hydrothermal liquefaction (HTL), is central to the article by Bayat et al. who consider the feasibility of converting food waste to bio-crude oil via hydrothermal liquefaction at moderate temperature and reaction times. From the treatment process developed, the authors indicated that low temperature HTL processes yielded positive net energy results, whereas increasing the operating temperature and reaction times increased the ECR over the unity, indicating that, under these operational conditions, no net energy was produced. The highest energy recovery was obtained when operated at $240^{\circ} \mathrm{C}$ for $30 \mathrm{~min}$, which yielded an ECR equal to 0.6. The bio-crude oil obtained was characterized utilizing Fourier Transform Ion Cyclotron Resonance Mass Spectroscopy (FT-ICR MS) obtaining that the majority of the compounds in the bio-crude oil produced at $240^{\circ} \mathrm{C}$ for $30 \mathrm{~min}$ were oxygen containing species, being the $\mathrm{O} 4$ the most abundant class of heteroatom-containing compounds.

The second theme, methane and hydrogen generation employing bioprocesses, focuses on the feasibility of blending wastes at different ratios to enhance the energy production. Sousa et al. propose a novel blending based on the combination of cereal, exhausted coffee wastes/liquor and pig slurry to highlight the importance of the $\mathrm{C} / \mathrm{N}$ ratio in the anaerobic digestion process. Additionally, the authors analyze the results through the lens of circular bio-economy bringing to the fore the inherent net positive energy stored in the wastes that could be recovered and recycled as biogas. This biogas could be subsequently used for future bio-energy solutions. Amado et al. study the anaerobic digestion of blends of coffee mucilage, cocoa mucilage and swine manure. The latter authors also focus their study not only on the methane, but also on the hydrogen production by means of dark fermentation processing of the waste blends. In these studies, the energy recovery potential of the residual wastes mixtures were determined. Finally, in the work carried out by Amado et al. anaerobic digestion and dark fermentation models were developed for the simulation of the bioprocesses,

\section{REFERENCES}

Osman, A. I., Abdelkader, A., Farrell, C., Rooney, D., and Morgan, K. (2019). Reusing, recycling and up-cycling of biomass: a review of practical and kinetic modelling approaches. Fuel Process. Technol. 192, 179-202. doi: 10.1016/j.fuproc.2019.04.026 obtaining accurate predictions, and beneficial information for process engineering and operation.

The third emergent theme in this issue is the energetic valorization of the products contained not only in the biogas, but also on the digestate. During the acidogenesis step of the anaerobic digestion, hydrogen and carbon dioxide are produced, along with a wide spectrum of fermented products such as Volatile Fatty Acids (VFA) and ethanol, amongst others. Nowadays, the VFA are usually produced from fossil sources and their potential production from renewable sources seems an exciting option. These chemical compounds, amongst others, acetate, propionate, butyrate and residual carbohydrates, could be converted into energy. In the work presented by Castilla-Archilla et al. the hydrogen generation as well as the VFA production during the continuous anaerobic treatment of the effluent generated in a brewing industry is studied using granular and flocculent cultures. In the literature many works have focused on hydrogen production, as the main product of the dark fermentation, without paying attention to the VFA generation; nonetheless, Castilla-Archilla et al. focused their work on the maximization of both, the hydrogen and VFA yield, to convert a simple wastewater treatment process into a combined wastewater treatmentchemical production bioprocess.

Finally, this volume deals with the breadth of researchable questions associated with the energy valorization of the food wastes, the feasibility of the processes and the importance of the wastes blending in the frame of the circular economy. Nowadays, the energy sources are changing to more sustainable ones, standing up the food wastes as one of the most interesting ones because of its double advantage, the waste treatment and the energy valorization. The answers to many of the questions emerging in the articles of this special issue remain elusive. But if good research raises more questions than it answers, then it would serve as a stimulus for further research focused on the energy valorization of the agro-food wastes in the frame of the circular economy.

\section{AUTHOR CONTRIBUTIONS}

FF prepared and approved the submitted version of the article.

\section{ACKNOWLEDGMENTS}

We are grateful to the authors who contributed manuscripts to this issue, and to the many reviewers and paper editors, who contributed their time and efforts to ensure the success and quality of the peer review process. Thank you to Jacek Dach and Jacek Makinia for co-editing this Research Topic.
USEPA (2020a). Advancing Sustainable Materials Management: 2018 Fact Sheet Assessing Trends in Materials Generation and Management in the United States. Washington, DC: USEPA.

USEPA (2020b). Inventory of US Greenhouse Gas
Emissions and Sinks: 1990-2018. Washington, DC:


Conflict of Interest: The author declares that the research was conducted in the absence of any commercial or financial relationships that could be construed as a potential conflict of interest.

Publisher's Note: All claims expressed in this article are solely those of the authors and do not necessarily represent those of their affiliated organizations, or those of the publisher, the editors and the reviewers. Any product that may be evaluated in this article, or claim that may be made by its manufacturer, is not guaranteed or endorsed by the publisher.

Copyright (c) 2022 Fernández Morales. This is an open-access article distributed under the terms of the Creative Commons Attribution License (CC BY). The use, distribution or reproduction in other forums is permitted, provided the original author(s) and the copyright owner(s) are credited and that the original publication in this journal is cited, in accordance with accepted academic practice. No use, distribution or reproduction is permitted which does not comply with these terms. 